\title{
Macrophage activation syndrome in a patient with axial spondyloarthritis on adalimumab
}

\author{
Rahaf Baker $^{1}$ • Jean W. Liew ${ }^{2,3}$ • Paul D. Simonson ${ }^{4} \cdot$ Lori A. Soma $^{4} \cdot$ Gordon Starkebaum $^{2}$ \\ Received: 25 October 2018 / Revised: 20 November 2018 / Accepted: 28 November 2018 / Published online: 7 December 2018 \\ (C) International League of Associations for Rheumatology (ILAR) 2018
}

\begin{abstract}
Macrophage activation syndrome (MAS) is a rare and potentially fatal condition characterized by excessive activation and uncontrolled proliferation of $\mathrm{T}$ lymphocytes and macrophages, leading to overwhelming systemic inflammation and cytokine release. MAS has been reported with viral infections, autoimmune disorders, malignancies, and medications. We describe a case of a patient with axial spondyloarthritis (axSpA) treated with adalimumab, who presented with MAS.
\end{abstract}

Keywords Adalimumab $\cdot$ Axial spondylitis $\cdot$ Fever $\cdot$ Hemophagocytic lymphohistiocytosis $\cdot$ Macrophage activation syndrome

To the Editor:

Macrophage activation syndrome (MAS) is a rare and potentially fatal condition characterized by excessive activation and uncontrolled proliferation of $\mathrm{T}$ lymphocytes and macrophages, leading to overwhelming systemic inflammation and cytokine release. MAS has been reported with viral infections, autoimmune disorders, malignancies, and medications. We describe a case of a patient with axial spondyloarthritis (axSpA) treated with adalimumab, who presented with MAS.

Rahaf Baker and Jean W. Liew contributed equally to this work.

KEY POINTS - MAS is a rare condition of systemic inflammation with high mortality; having a strong index of suspicion can lower mortality in these patients.

- Medications, including TNF inhibitors, should be considered as possible triggers for MAS.

- Consider high-dose steroids and anakinra, either alone or in combination, for the treatment of MAS. If a medication is suspected, remove the offending agent.

Jean W. Liew

jwliew@uw.edu

Rahaf Baker

rahafb@uw.edu

Paul D. Simonson

psimonso@uw.edu

Lori A. Soma

somal@uw.edu

\section{Case report}

A 34-year-old Middle Eastern man with long-standing HLAB27-positive axSpA on adalimumab presented with several days of persistent fevers. AxSpA had been diagnosed on the basis of a history of recurrent iritis, patellar tendon enthesitis, and inflammatory lower back pain. The back pain, although initially responsive, became refractory to non-steroidal antiinflammatory medications and a sacroiliac joint steroid injection. Adalimumab was started in April 2018, and for the next

Gordon Starkebaum gas1@uw.edu

1 University of Washington School of Medicine, Seattle, WA, USA

2 Division of Rheumatology, Department of Medicine, University of Washington School of Medicine, Seattle, WA, USA

3 University of Washington, 1959 NE Pacific St, BB561, Seattle, WA 98195, USA

4 Department of Laboratory Medicine, Division of Hematopathology, University of Washington School of Medicine, Seattle, WA, USA 
2.5 months, he had dramatic improvement in his inflammatory back pain, and no extra-articular manifestations. In June 2018, he presented to the hospital and endorsed 4 days of high fevers with mild lower chest discomfort and cough. He described unremitting fevers that occurred multiple times daily, which were associated with significant weakness and rigors. The review of systems was otherwise negative. He had no other pertinent past medical history or medications. His family history was non-contributory. His social history was notable for moving to the USA from Saudi Arabia 10 years ago with recent, frequent travel around the USA and Mexico. He had traveled to Las Vegas for a work conference a few days prior to his presentation.

On admission, his temperature was $40.2^{\circ} \mathrm{C}$, blood pressure was $129 / 68 \mathrm{~mm} / \mathrm{Hg}$, and pulse was 60 beats per minute. He was ill-appearing and his physical exam was otherwise only notable for splenomegaly with tenderness on palpation. His initial labs revealed lymphopenia (absolute lymphocyte count 650 cells $/ \mu \mathrm{L}$ ), mild anemia (hemoglobin $12 \mathrm{~g} / \mathrm{dL}$ ), thrombocytopenia (132,000 cells $/ \mu \mathrm{L}$ ), and transaminitis (AST $53 \mathrm{U} / \mathrm{L}$, ALT $76 \mathrm{U} / \mathrm{L}$ ). Erythrocyte sedimentation rate (ESR) was $42 \mathrm{~mm} / \mathrm{h}$ and C-reactive protein (CRP) was $202 \mathrm{mg} / \mathrm{dL}$. An extensive infectious disease workup was undertaken, with all tests reported as negative (Table 1). Computed tomography (CT) of the chest, abdomen, and pelvis showed mild splenomegaly with residual thymic tissue and no lymphadenopathy.

After a week of hospitalization, the patient remained febrile despite treatment with antipyretics. He developed a transient, faint, erythematous maculopapular rash over his trunk.
Further labs demonstrated elevated ferritin $(2312 \mathrm{mg} / \mathrm{dL})$, fibrinogen $(871 \mathrm{mg} / \mathrm{dL})$, and triglycerides $(289 \mathrm{mg} / \mathrm{dL})$. CRP peaked at $400 \mathrm{mg} / \mathrm{dL}$. A diagnosis of MAS was considered. On the seventh day of hospitalization, he was started on anakinra $100 \mathrm{mg}$ twice daily without adequate fever control; thus, oral prednisone $60 \mathrm{mg}$ daily was added. He quickly defervesced with improvement of his condition, labs, and inflammatory markers (Fig. 1). A bone marrow biopsy, which was obtained on hospital day 7 , showed erythroid hyperplasia and hemophagocytic histiocytes without evidence of malignancy (Fig. 2). Soluble interleukin-2 receptor levels, however, were low. After an 11-day hospitalization, he was discharged on prednisone $60 \mathrm{mg}$ daily and anakinra $100 \mathrm{mg}$ once daily. Adalimumab was completely discontinued. Upon outpatient follow-up, he had continued symptomatic improvement with normalization of the ESR, CRP, ferritin, and fibrinogen. He was tapered off prednisone over 2 months but his inflammatory back pain returned.

\section{Discussion}

MAS is a potentially fatal syndrome that can present in patients with inflammatory conditions and is considered to be similar to hemophagocytic lymphohistiocytosis (HLH) $[1,2]$. The finding of abundant activated hemophagocytic macrophages, or histiocytes, has led to their classification as a histiocytic disorder [3]. The underlying pathogenesis of MAS is poorly understood, but it is proposed to be triggered by an
Table 1 Summary of workup for unexplained fever

\begin{tabular}{ll}
\hline Infectious category & Tests returned negative \\
\hline Viral & Serum Ebstein-Barr virus monospot and PCR; serum cytomegalovirus PCR; \\
& serum herpes simplex virus 1 and 2 PCR, serum varicella zoster virus PCR \\
& Nasopharyngeal rapid influenza A and B PCR \\
& Respiratory viral panel PCR: bocavirus, metapneumovirus, adenovirus, \\
& parainfluenza 1-4, respiratory syncytial virus, coronavirus, rhinovirus \\
& Serum West Nile virus IgM and IgG \\
& Human immunodeficiency virus antibody/antigen 4th-generation screen \\
& Hepatitis B virus surface antigen, surface antibody, and core antibody \\
& Hepatitis C virus antibody screen \\
& Group A Streptocccus by rapid detection \\
& Streptococcus pneumoniae urine antigen \\
Bacterial & Legionella urine antigen \\
& Serum Leptospira IgM \\
& Syphilis IgG antibody \\
& Quantiferon-Gold tuberculosis \\
& Histoplasma urine antigen \\
Serum Coccidioides IgG and IgM & Cryptococcus serum antigen \\
Fangal & Malaria thick and thin smear \\
\hline &
\end{tabular}

$P C R$, polymerase chain reaction 


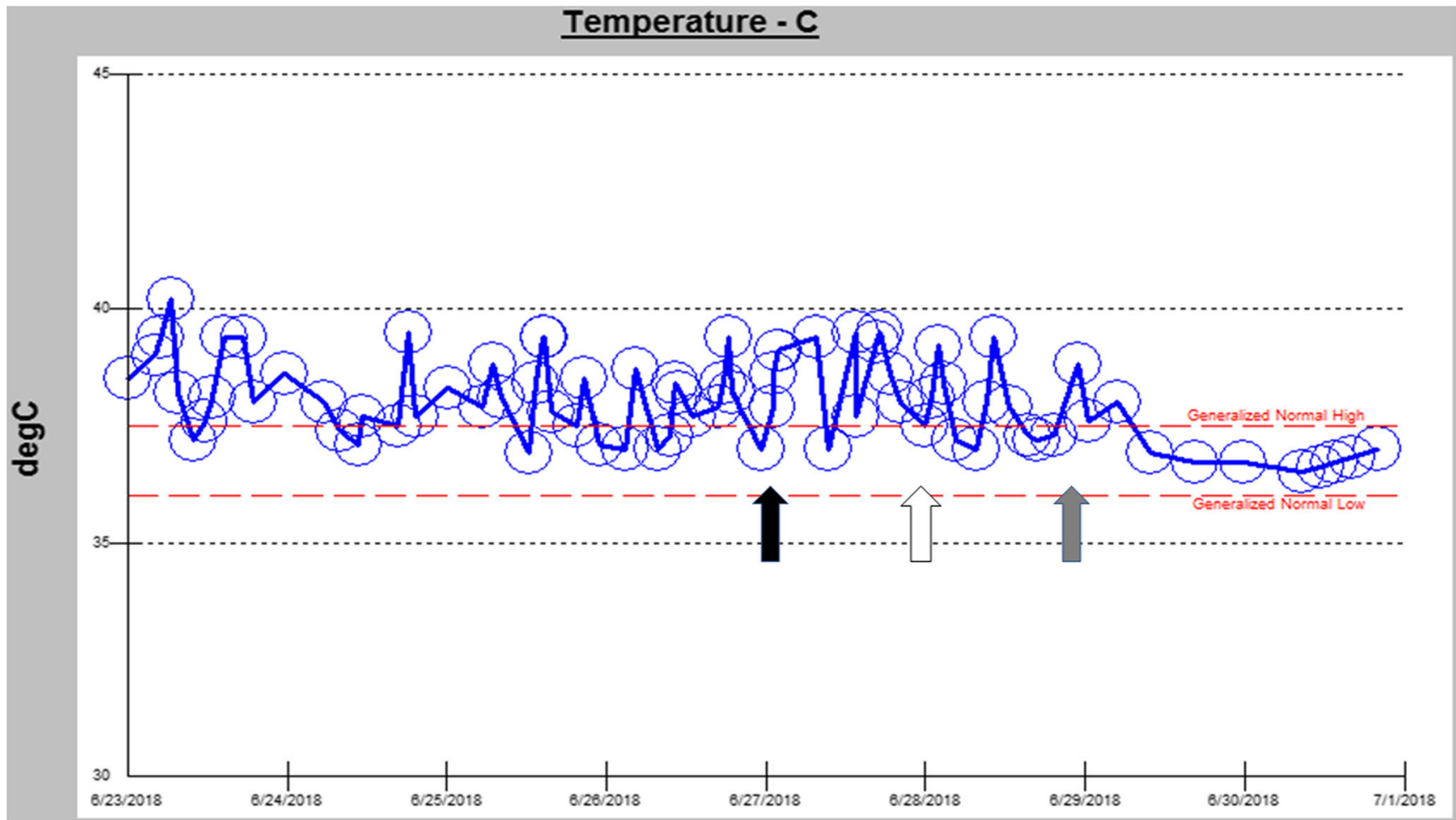

Fig. 1 Fever curve during hospital stay. The black arrow indicates the initiation of anakinra $100 \mathrm{mg}$ daily. The white arrow indicates the initiation of anakinra $100 \mathrm{mg}$ twice daily. The gray arrow indicates the initiation of prednisone $60 \mathrm{mg}$ daily with continued twice daily anakinra injections

inciting event such as infection, malignancy, autoimmune conditions, or drugs, that leads to immune dysregulation [4]. The resultant overwhelming cytokine storm drives phagocytosis of blood cell precursors and the infiltration of macrophages into tissues, causing multiorgan dysfunction. Currently, there are no diagnostic criteria for MAS in adults, and the proposed classification criteria rely on our understanding from the pediatric population [1]. The findings of high fevers, cytopenias, hyperferritinemia, and hypertriglyceridemia should alert the clinician to the possibility of MAS.
Although significantly elevated ferritin is specific for HLH in pediatrics, it is not as specific to HLH or MAS in the adult population [5]. Evidence of hemophagocytic cells on bone marrow biopsy is not required for diagnosis and is not always found on presentation in MAS.

The most consistent diagnosis for our patient was MAS, as he had high persistent fevers without an infectious cause, lymphopenia and anemia, marked hyperferritinemia, hypertriglyceridemia, splenomegaly, and the presence of hemophagocytes on bone marrow biopsy. The diagnosis of

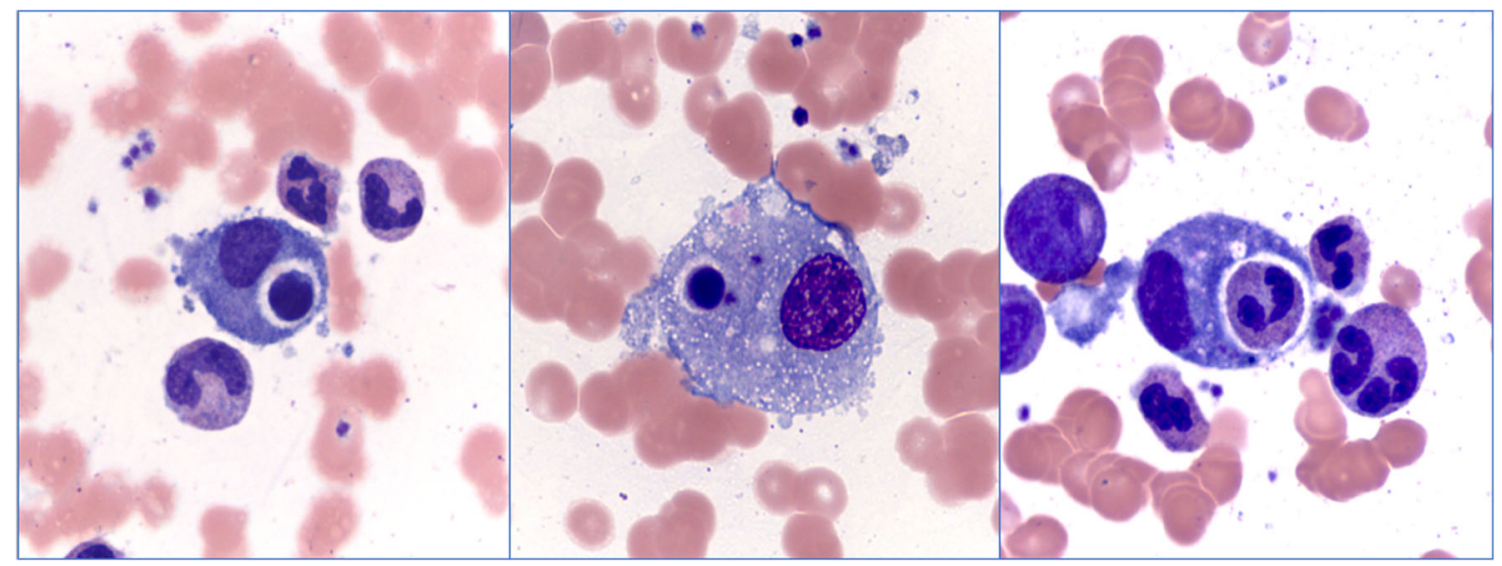

Fig. 2 Hemophagocytic histiocytes. The images are those of hemophagocytic histiocytes seen in a bone marrow aspirate smear. The left two images show histiocytes with engulfed cells, consistent with degenerated hematopoietic cells. The image on the right shows a histiocyte with an engulfed neutrophil 
adult-onset Still's disease (AoSD) was excluded due to his axSpA [6]. The leading explanations for his MAS were adalimumab, an undetected viral infection, or his underlying axSpA.

Infection, particularly viral, is the most common reported cause of MAS cited in the literature [2]. Our patient had extensive infectious workup that was negative; however, his MAS may have been triggered by an undetected virus. In rheumatologic conditions, MAS has been associated with underlying activity of systemic juvenile idiopathic arthritis and AOSD, and in rare cases of systemic lupus erythematosus [1]. $\mathrm{SpA}$ is rarely associated with MAS; only three were found in our review of the literature (Table 2). Of these three cases, only one occurred in the absence of TNF inhibitor use or clear source of infection [7]. Our patient had well-controlled SpA that was stable prior to presentation; therefore, we felt that SpA was a less likely trigger for his MAS.

Recently, MAS has been reported more frequently in association with TNF inhibitor use, although it is unclear whether this is due to heightened clinician awareness or increasing incidence. On our literature review, we found 10 reports of MAS associated with etanercept, infliximab, or adalimumab (Table 3). Of the two cases that described the timing of MAS relative to TNF inhibitor administration, one was in a patient with RA 2 months after discontinuation of etanercept, and one was in AoSD 2 months after initiation of adalimumab [12, 14]. Four of the cases reported had associated infections, including visceral leishmaniasis, disseminated histoplasmosis, liver abscess, or primary EBV, which were felt to be the primary trigger for MAS, though the TNF inhibitor was implicated as a contributing risk factor for the infection $[8,13,15]$. It is plausible that adalimumab triggered MAS in our patient as he presented at 2.5 months after initiation of adalimumab, which is consistent with the timeline from other case reports, and he had no obvious infection.

The pathogenesis of MAS secondary to TNF inhibitors is unknown. These medications have been successful in treating some refractory cases of MAS, but their use may also rarely induce or aggravate autoimmune diseases, or trigger MAS in the setting of infection [1]. It has been proposed that TNF inhibitor blockade of macrophage activity is coupled with a compensatory immune system activation and rebound cytokine response [16]. This leads to an overall immune system dysregulation and may trigger hemophagocytosis. The explanation for this paradoxical effect on immune response will require further research.

As for the treatment of MAS, we note that in MAS associated with TNF inhibitors only, six of the eight patients had clinical and laboratory improvement after treatment with highdose corticosteroids. Two patients died despite receiving highdose corticosteroids; however, these patients presented with severe or late systemic disease that was previously not well controlled on prednisone [9, 12]. In the cases of MAS with an associated infection, three of the four patients received highdose corticosteroids in addition to treatment of underlying infection, and all four patients responded well and survived $[8,13,15]$. In the three reported cases of MAS in SpA, all three patients received high-dose prednisone and clinically stabilized [7, 8]. Dual treatment with high-dose steroids and anakinra, an IL-1 receptor antagonist, induced remission in our patient. Both agents have been shown to rapidly induce remission and ameliorate the cytokine storm in refractory and severe cases of MAS [4]. Anakinra was trialed first in our patient given his prolonged and high fevers, but given the

Table 2 Case reports of MAS in patients with axial spondyloarthritis

\begin{tabular}{|c|c|c|c|c|c|c|}
\hline Citation & Age & Gender & $\begin{array}{l}\text { Underlying } \\
\text { conditions }\end{array}$ & $\begin{array}{l}\text { TNF } \\
\text { inhibitor used }\end{array}$ & Treatment & Outcome \\
\hline Larroche et al. [5] & 37 & M & $\begin{array}{l}\text { Crohn's disease with axial } \\
\text { spondyloarthritis treated } \\
\text { on infliximab. Patient had } \\
\text { EBV primary infection }\end{array}$ & Infliximab & $\begin{array}{l}\text { IV immunoglobulin }(2 \mathrm{~g} / \mathrm{kg}) \\
\text { and } 3 \text { boluses of } \\
\text { methyplrednisolone }\end{array}$ & $\begin{array}{l}\text { Seroconversion } 2 \text { months } \\
\text { later with negative EBV PCR }\end{array}$ \\
\hline Larroche et al. [5] & 40 & M & $\begin{array}{l}\text { Ankylosing spondylitis on } \\
\text { infliximab. Patient had } \\
\text { a liver abscess }\end{array}$ & Infliximab & $\begin{array}{l}\text { Antibiotics (amoxicillin, } \\
\text { clavulonic acid, } \\
\text { erythromycin), IV } \\
\text { immunoglobulin } \\
\text { ( } 2 \mathrm{~g} / \mathrm{kg}) \text {, and } 7 \\
\text { methylprednisolone } \\
\text { boluses followed by } \\
\text { prednisone }\end{array}$ & Healing of abscess \\
\hline Lou et al. [6] & 42 & $\mathrm{~F}$ & Ankylosing spondylitis & None & Prednisolone (60 mg/day) & $\begin{array}{l}\text { Laboratory improvement } \\
\text { within } 2 \text { weeks. } \\
\text { Clinically stable without } \\
\text { relapse at } 6 \text { months }\end{array}$ \\
\hline
\end{tabular}

$E B V$, Epstein Barr virus; $P C R$, polymerase chain reaction 


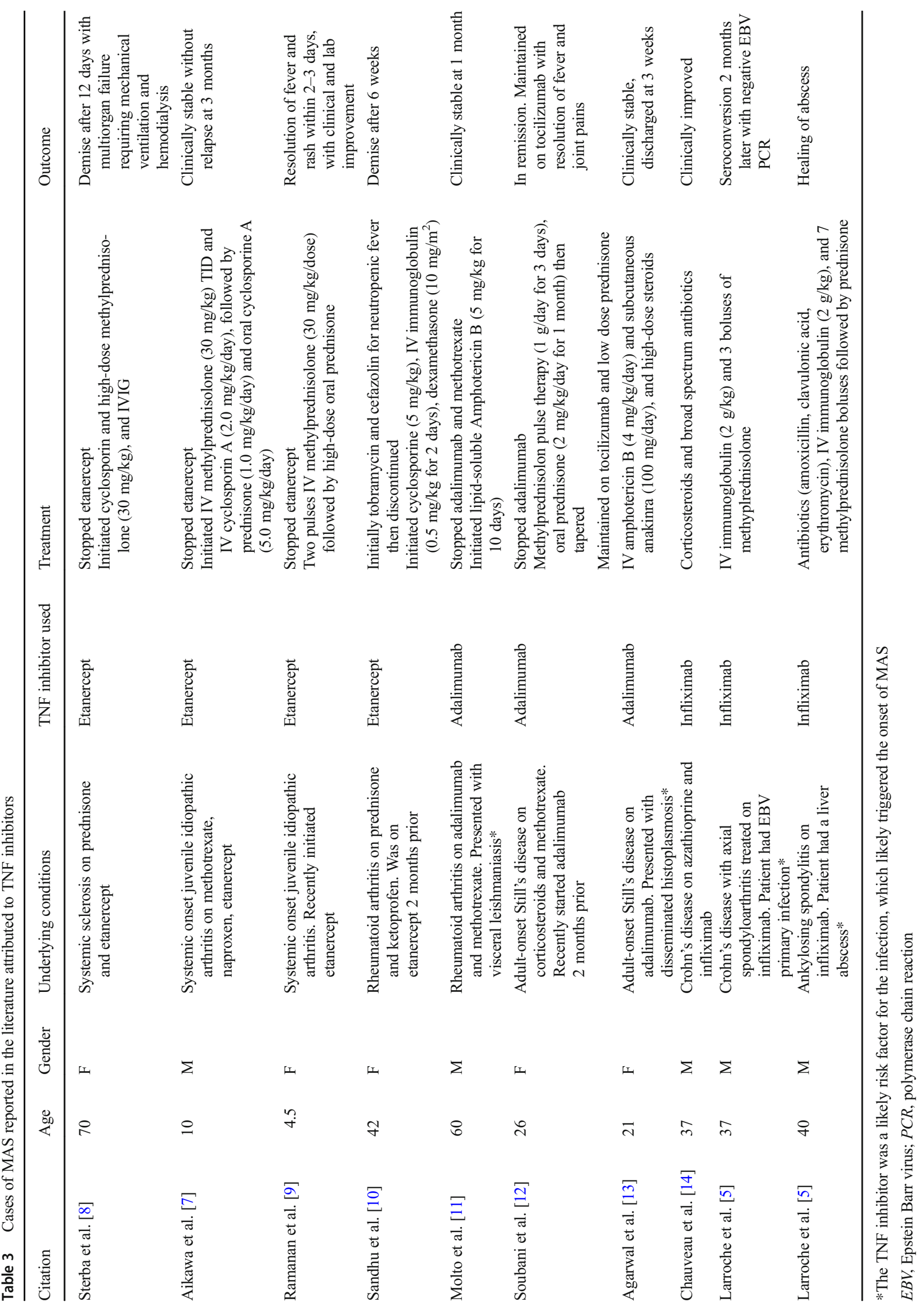


duration of symptoms and the likely presence of other cytokines besides IL-1, it alone was not sufficient in inducing remission.

In conclusion, it is important to recognize MAS as a possible life-threatening complication of autoimmune and inflammatory diseases. Currently, the diagnosis of MAS relies heavily on the pediatric diagnostic criteria, and the treatment on case reports and case series in adults. It is important to increase awareness of this rare disease among clinicians in order to prevent mortality and improve outcomes of these patients.

\section{Compliance with ethical standards}

Disclosures None.

Publisher's Note Springer Nature remains neutral with regard to jurisdictional claims in published maps and institutional affiliations.

\section{References}

1. Ravelli A, Minoia F, Davi S et al (2016) 2016 classification criteria for macrophage activation syndrome complicating systemic juvenile idiopathic arthritis. Ann Rheum Dis 75:481-489

2. Schram AM, Berliner N (2015) How I treat hemophagocytic lymphohistocytosis in the adult patient. Blood 125:2908-2914

3. Emile JF, Abla O, Fraitag S, Horne A, Haroche J, Donadieu J, Requena-Caballero L, Jordan MB, Abdel-Wahab O, Allen CE, Charlotte F, Diamond EL, Egeler RM, Fischer A, Herrera JG, Henter JI, Janku F, Merad M, Picarsic J, Rodriguez-Galindo C, Rollins BJ, Tazi A, Vassallo R, Weiss LM, for the Histiocyte Society (2016) Revised classification of histiocytoses and neoplasms of the macrophage-dendritic cell lineages. Blood 127: 2672-2681

4. Grom AA, Horne A, De Benedetti F (2016) Macrophage activation syndrome in the era of biologic therapy. Nat Rev Rheumatol 12: 259-268
5. Schram AM, Campigotto F, Mullally A et al (2015) Marked hyperferritinemia does not predict for HLH in the adult population. Blood 10:602-607

6. Feist E, Mitrovic S, Fautrel B (2018) Mechanisms, biomarkers and targets for adult-onset Still's disease. Nat Rev Rheumatol 14:603618

7. Lou YJ, Jin J, Mai QY (2007) Ankylosing spondylitis presenting with macrophage activation syndrome. Clin Rheumatol 26(11): 1929-1930

8. Larroche C, Falgarone G, Dumont Fischer D, Dhote R (2010) Syndrome d'activation macrophagique sous biothérapies: deux cas. Rev Med Interne 31S:S404-S501. https://doi.org/10.1016/j. revmed.2010.10.181.

9. Sterba G, Sterba Y, Stempel C, Blank J, Azor E, Gomez L (2010) Macrophage activation syndrome induced by etanercept in a patient with systemic sclerosis. Isr Med Assoc J 12:443-445

10. Aikawa NE, Carvalho JF, Bonfa E et al (2009) Macrophage activation syndrome associated with etanercept in a child with systemic onset juvenile idiopathic arthritis. Isr Med Assoc J 11:635-636

11. Ramanan AV, Schneider R (2003) Macrophage activation syndrome following initiation of etanercept in a child with systemic onset juvenile rheumatoid arthritis. J Rheumatol 30:401-403

12. Sandhu C, Chesney A, Piliotis E, Buckstein R, Koren S (2007) Macrophage activation syndrome after etanercept treatment. J Rheumatol 34:241-242

13. Molto A, Mateo L, Lloveras N et al (2010) Visceral leishmaniasis and macrophagic activation syndrome in a patient with rheumatoid arthritis under treatment with adalimumab. Joint Bone Spine 77: 271-273

14. Soubani L, Dridi L, Abdelghani KB et al (2014) Possible macrophage activation syndrome following initiation of adalimumab in a patient with adult-onset still's disease. Pan Afr Med J 17:94

15. Agarwal S, Moodley J, Goel GA et al (2011) A rare trigger for macrophage activation syndrome. Rheumatol Int 31:405-407

16. Chauveau E, Terrier F, Casassus-Builble D et al (2005) Syndrome d'activation macrophagique apres traitement par infliximab pour maladie de crohn fistulisee. Presse Med 34:583-584 